\title{
Research on the Service Mode of Creative Products Design of Bengbu University under the Powerful Industrial City Strategy
}

\author{
Li Zhang*, Haixia Sun \\ School of Art and Design, Bengbu University, 233000 Bengbu, Anhui, China
}

\begin{abstract}
Under the perspective of powerful industrial city strategy and based on the creative product design in Bengbu University, this paper constructs a service mode that is compatible with the creative product design in Bengbu University by combing the product design service theory according to Bengbu University's positioning in application-oriented university.By strengthening the supply of design service and adopting the combination of multiple innovative measures of regional culture, university-enterprise cooperation, studio and craftsmanship spirit, etc., it strives to enhance student's professional practice ability comprehensively, to promote enterprise's research and innovation level. It is aimed to cultivate highquality practical talents that are suitable for supporting the development of powerful industrial. It also provides referential theoretical basis and reference for the related researches on product design service.
\end{abstract}

\section{Powerful Industrial City}

Emphasizing on the powerful industrial city strategy is a comprehensive representation of Bengbu's following of the demands on high-quality development. At the same time, the instructive ideology of "science and technology are the primary productive force"should be popularized all around, which can facilitate the implementation of the Scientific Outlook on Development. The significant service capacity of innovation should be extinguished, indicating its support to the economy growth and the development of society. The allocation of technology resources should be improved continuously, thriving in enhancing the technology level, highlighting the important role of the powerful industrial city strategy and the service provided by technology outcomes to the society.In summary, the goal of powerful industrial city strategy is to achieve accelerated development and to take new cultural creativity and services as the focus of reform [1]. The key is to promote industrial transformation and upgrading,strengthen innovative services,enhance industrial value and the ability in providing professional services,forming the development model of "manufacturing + service". At the same time, it is also necessary to explore technological innovation actively, promote local industries and local universities to conduct joint research and cooperation in innovation, and to construct R \& D service platforms jointly. It is devoted to build Bengbu into a core base for the development of important high-tech industries under the "Industrial Strong City", and to enhance the level of urban development, thereby enhancing regional competitiveness.
Based on the exposition above, it is not hard to find that if we want to realize the construction of powerful industrial city, not only shall we emphasize the development of high-tech industries and relevant services, but also have to cultivate comprehensive talents that are capable of conduct research and design. Those talents are the most direct and power human resources for promoting the construction of powerful industrial city. Therefore, regional universities should make their contribution by responding to the urgent demand of delivering relevant talents for the construction of local economy and development of society. At the same time, local universities have to adjust their own direction and scientific research plan on talents' cultivation according to the principle of targeted development, the local economic development dynamics and structural characteristics of the new industry.So,the development of professionals and talents' training can better serve the industrial transformation and upgrading,as well as the development of powerful industrial city. Therefore, Bengbu University has to fully utilize their design studio with advanced equipment and their featured major of creative products design to construct the service platform. On one hand, this service model can enhance the capability of independent innovation of Bengbu university,fasten the conversion of research results and realize the merging of manufacturing and teaching; on the other hand, it could utilize the school's advantages in talent and equipment in the cooperation with enterprises, to provide support in research and development for the enterprises and to deliver talents to them. It can create a correlative dependence between enterprises and universities,increase the technology level of enterprise's development, thus promote the development of local economy. 


\section{Product Design Service}

From the perspective of design science, products are displayed in the practical physical form, while service is an intangible value that derived from physical form. It can be seen that product and service have fundamentally different attributes [2]. However, with the advancing of Made in China 2025 strategy and Industrial 4.0 strategy, the design philosophy that oriented by creating service value has become the research hotspot of product design.Only by integrating "featured service"into the research and manufacture of products can the enterprise's new product gain their position on the market and acquire the recognition in the industry. And that has become the breakthrough direction for current product design and innovation[3]. As a brand-new research and development mode, it conducts systematic planning and studying on the new product from the aspects of concepts and services[4]. For product design, the intangible service has taken the leading role in developing, and products have been converted to a platform that displays service. How to provide a more valuable service is the core of the transformation from "practical economy"to"intangible economy"For enterprises, this new model of comprehensive optimization is the most effective way.Eventually,it will give enterprises more features of their own, and distinguish them in the market.Their practical products will be attached with invisible added value, realizing a benign development,as well as achieving the goals of social benefit and economic benefit.

Therefore, as a regional university,Bengbu University should fully utilize their major of creative product design,combine it with the enterprises that manufacture

creative products and provide supporting service. A comprehensive service platform for product design should be launched, as to provide professional talents and technical supports for the design innovation of enterprises. Cooperating in designing and building creative products that embedded with local cultural features can push the research and development innovation of product design. Culture resources should be applied to improve enterprise's resource allocation, and the transformation of creativity economy can realize enterprise's sustainable development. It meets the demands of industrial transformation and upgrading under the powerful industrial city strategy, and further realize the inheritance of culture and creates income for the economy.

\section{Creative Product Design}

In recent year, creative product has been enrolled in many scholar's research scope. It is a byproduct of the growing creativity industry. Creative product design is practical product presented by a creative process that uses methods in design science. Among which the creativity connotation is the core, making the product has both invisible creative value and practical value [5]. Creative products have extreme high innovativeness and originality. Creative talents and technologies are the core. And by the cooperation between professionals with different skills and the design ideology that converts mined innovative idea to creative products, the industrial cluster effect will be realized, which could further be used to present the high added value in the service of creative products[6].Creative products value analysis figure 1.

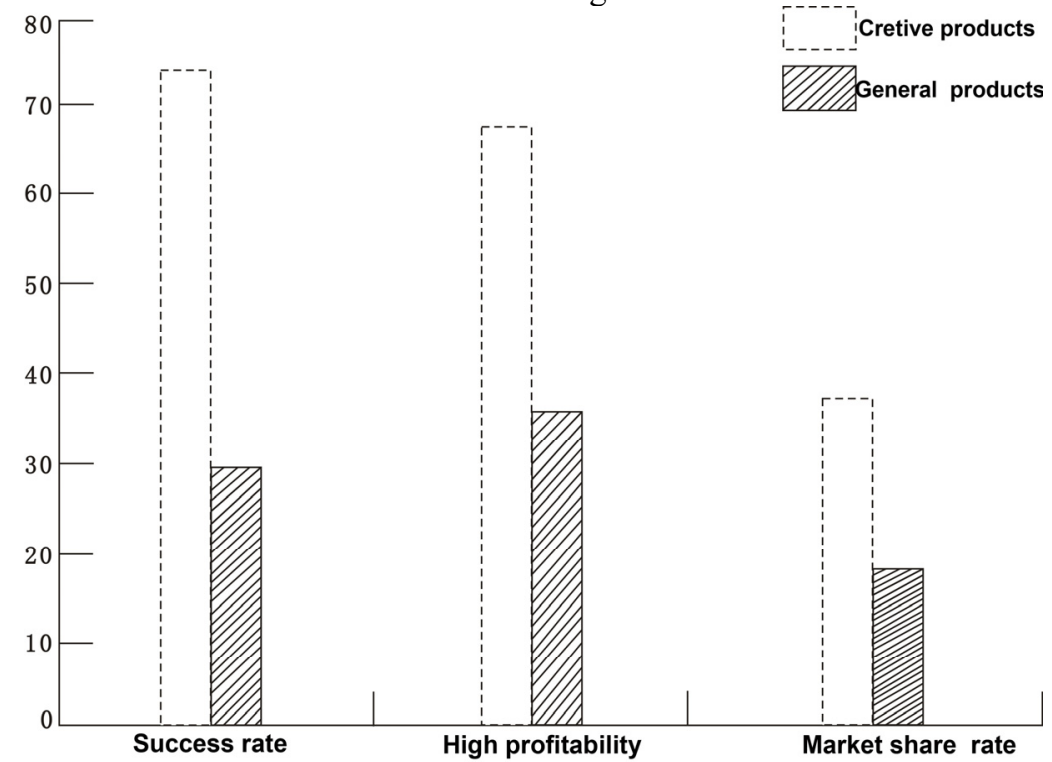

Figure 1. Creative Products Value Analysis

The rising of industry drives demand of talents that have professional creative products. As a university that possesses creative product major, its role should be played, as to display the university's visible value and invisible value in cultivating professional talents. This new operation pattern is based on the practice of university' creative product design, and to build a featured brand for creative products. Such pattern can not only present the university's featured education philosophy, expand its social impact, realize the 
integration of humanistic quality and artistic practice,but also guaranteed the same direction of the school's cultivation of talents and the development of industry, that further improve the image of regional brand and the promotion of related industry.

As for now,some well-known universities in China has formed a complete research, develop and service system for creative products. Comparing with other universities,Bengbu University has not formed a complete industrial service system, no matter from the design to production, or to the cooperated promotion and the construction of service platform.

There is a great significance in researching the development path of the creative products in Bengbu University by combining with the rising service mode under the powerful industrial city strategy. The powerful industrial city strategy put forward new demands for the development of creativity industry, as well as the philosophy of industry transformation and upgrading.From the aspect of creative products design, Bengbu University has featured product design major.If its duty of service has to be distinguished, the links of talents cultivation, university-enterprise cooperation and investment in creativity industry should be emphasized.The creative mind of the major of product design should be strengthened and the creative spirit should be expanded, to form an atmosphere that facilitates creative product design.Combining with the university's professional talents and hardware equipment, the cooperated research with corresponding enterprises should be conducted in various phases like creative design phase,production phase and cooperation phase, realizing a merging of production, learning and researching. The resource advantages that owned by the region should be fully utilized in actively designing the creative products that have its own features and in correspondence with the consumption demand of the market. Such creativity resource could be converted to a new industry, and thus promote the transformation and upgrading of the traditional industries, realizing a sustainable development. The service platform for creative products design in Bengbu university with distinguished characteristics should be advanced,making it an effective method in serving the powerful industrial city strategy.

\section{Construction method of the Service Mode for Creative Product Design in Bengbu University}

The construction framework of Bengbu university creative product design service model is shown in Figure 2.

\subsection{Integrated with regional culture}

Utilizing regional culture resource, converting it to creative products and making it in correspondence with mass demand are the trend of creativity industry in the future. Regional features culture is an important inspiration source for creativity product design in
Bengbu University, it can not only distinguish the creative products from the similar products in the markets, but also present the regional characteristics of talents cultivation.Therefore, Bengbu University's advantages of having special cultural resources should be fully utilized. Typical featured cultures like Huai River Culture, Dayu Culture have very significant research value.It should be integrated into the design philosophy of creative products.During the practice process, the value connotations and cultural elements of regional cultural resources should be deeply mined.And those cultural elements should be extracted and integrated by adopting creative design methods. The philosophy of creative design can not only realize the innovation and inheritance of regional culture, but also provide new ideas and schemes for the design of creative products, thus increase the value and market competitiveness of creative product's design. In the same time, taking the creative product design in Bengbu University as the service platform, the model effect of art education in Bengbu University can be distinguished. It can further promote the construction of economy and culture by creative products and provide concrete power for promoting the creative product's brand and the employment of local talents in the industry.

\subsection{University-Enterprise Cooperation}

The strategy of a powerful industrial city requires that industries continue to be upgraded. Therefore, Bengbu University needs to build a talent cultivating mechanism that combines with industrial development to cultivate talents who can undertake the strategy of building an industrially strong city. University-Enterprise cooperation can help schools cultivate applied talents who meet enterprise development's needs through various forms of cooperation, in or out of school. It is also an important method of talent cultivating. Therefore, it should explore a new model of Bengbu University creative product design University-Enterprise cooperation that conforms to the strategy of the powerful industrial city and make it serve the strategy of the powerful industrial city.Bengbu University has established a product design practice center at present. Therefore, it can integrate the respective superior resources and conduct cooperation in creative product development and design, professional talent cultivating plans, discipline construction, make and practice teaching plans depending on its schools-enterprises cooperation of creative product design.

This mode of cooperation organically combines enterprise design needs and professional practice links, cooperates with relevant companies to develop actual creative products, further close the distance between students and actual products,drive students' enthusiasm for professional learning, and strengthening the training of actual creative products design ability for students to achieve the purpose of university talents cultivating. It deeply reflects the integration of practical teaching, creative product development, technology research and development, creative product incubation, trainingpracticing 


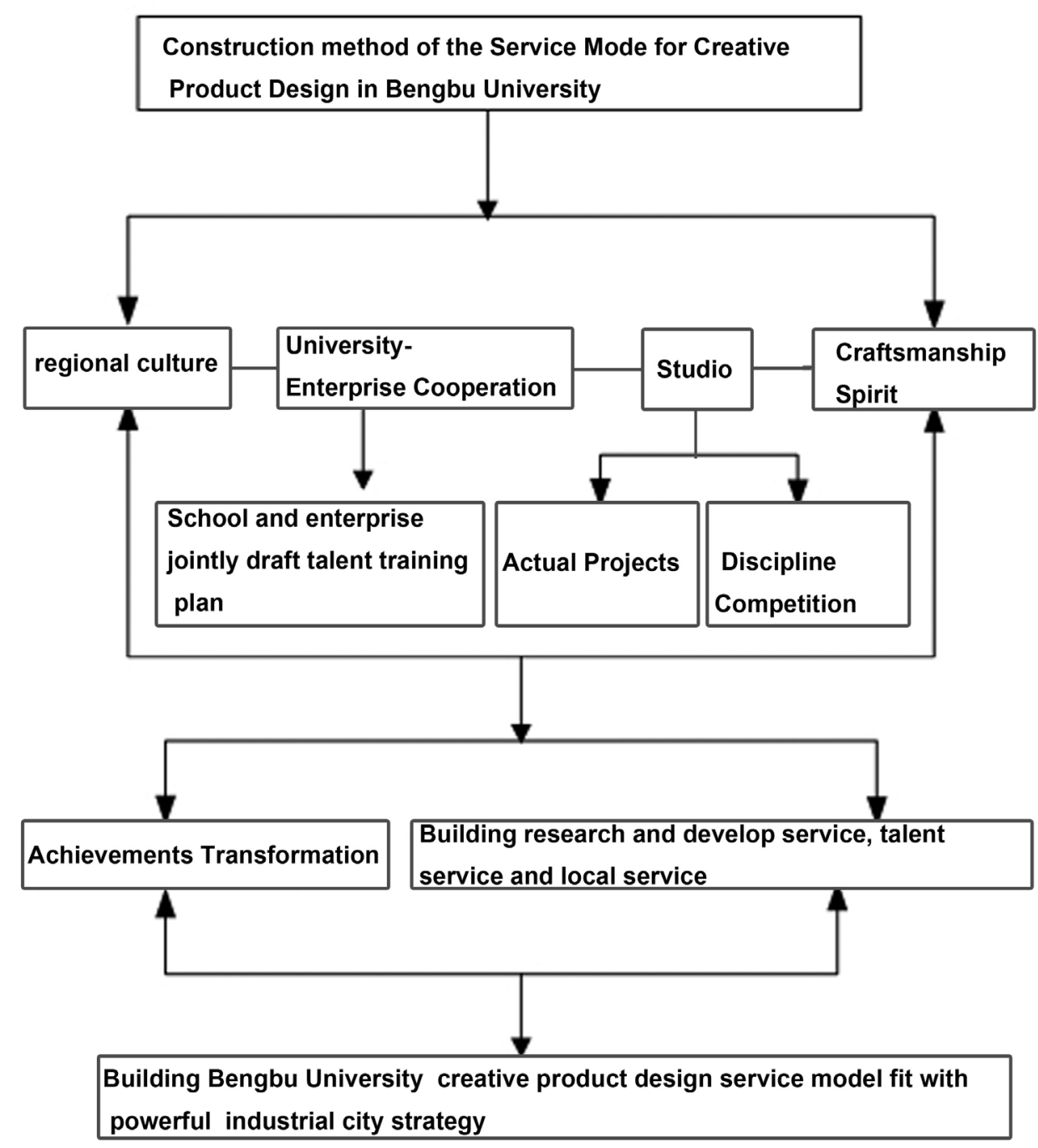

Figure 2. The Construction Framework of Bengbu University Creative Product Design Service Model

combination, brings the most satisfactory design concepts to enterprises with the lowest resource consumption and cost input, promotes enterprise product upgrades, renews and diversification of product types, to improve the success rate of enterprise product development and market share, to achieve a win-win result between school and enterprises and reach a good cooperative relationship. Taking this opportunity, it will further create a creative product design service platform with a perfect system to promote the transformation of design achievements and provide service support to enterprises research and development innovation and industrial development.
Bengbu university creative product design school enterprise cooperation service model is shown in Figure 3.

The specific methods of University-Enterprise cooperation can start from the following two aspects:

\subsubsection{Actual Projects}

Bengbu University product design form good and deeper cooperation and interact through the actual projects.

Enterprise research and development project, the scientific research project applied by teachers, the scientific research project which has students participate in and others can make up actual projects. By 


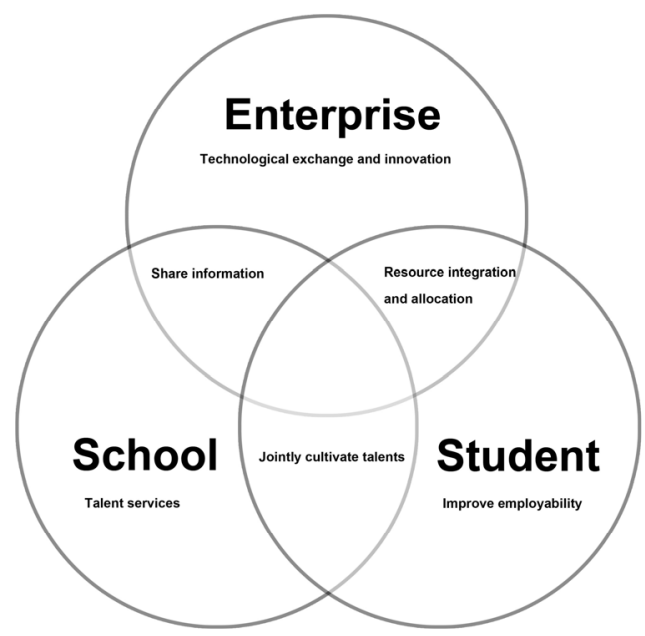

Figure 3. Bengbu University Creative Product Design School Enterprise Cooperation Service Model

process; it highlights the function of serving society, makes the preparation for students to do relevant work after graduation, and cultivate new applied talents who meet the needs of constructing a powerful industrial city.

\subsubsection{Discipline Competition}

Professional discipline competition is an important and nonnegligible teaching method which can stimulate students' enthusiasm to participate in professional learning. It can not only enrich the courses teaching methods but also can promote the construction of professional courses, promote the enterprises'technology innovation, promote the transformation of competitions' achievements, further improve the integration of production, learning and research to achieve win-win result between schools and enterprises.

\subsection{Studio}

"Studio" is a new type of practical teaching model based on University-Enterprise cooperation and actual projects,which is recognized and adopted by more and more educational circles. The cultivating model which bring comprehensive and actual projects practice in the studio for students to complete and let teachers and professional personnel enter the school to guide and comment, can further promote the improvement of professional practical skills, improve innovative thinking, and enhance the teamwork capabilities based on satisfying students to become highly skilled talents who meet the needs of enterprises and markets. Therefore, Bengbu University should set up the studios for creative product design, make responsibilities and management plans of studios and relevant talent cultivating programs to achieve the small-sized class and distinctive talent cultivating. In order to increase the employment rate of students after graduation and convey competitive talents, it is necessary to carry out diversified cooperation with enterprises through studios. At the same time, in order to promote the teaching achievements innovation, the studio can combine practical courses and projects to form the integration of teaching, research and development and social services. In the studio, students' creative product design achievements can be promoted and displayed through design exhibitions or professional discipline competitions, and design culture weeks, so that it can build a good service platform through the studio and provide services for the disciplines' development and the construction of a powerful industrial city.

\subsection{Craftsmanship Spirit}

In 2016, Premier Li Keqiang proposed the craftsmanship spirit in the government report which reflects the importance attached to the manufacturing industry. This is consistent with the strategic objective of a powerful industrial city that they both focus on the development of the manufacturing industry. The core of the manufacturing industry is product design while the industrial development of the manufacturing industry depends on product design and universities are training bases that convey professional talents for product design. Therefore, it is necessary for universities to strengthen the education of craftsmanship spirit for students when cultivating product design professional talents.

"Keep improving, be brave to explore, practice and innovate" is the ideology core of craftsmanship spirit [7]. The cultivating requirements of product design major for students advocate the pursuit of perfection and the spirit of service which pull out all the stops. Hence, the core of these two concepts is consistent. Incorporating craftsmanship spirit into Bengbu University creative product design practice teaching, combining UniversityEnterprise cooperation and studio model can help students better establish professional ideals and learning goals, enhance students' enthusiasm for major learning, develop them a positive and focused learning attitude, enable students to be creative, willing to innovate, enhance students' innovative ability, so as to create more excellent creative product design works, thus contributing to the development of a powerful industrial city. 


\section{Conclusion}

In conclusion, this paper systematically analyzes, summarizes, integrates, and proposes a service model suitable for Bengbu University's creative product design under the guidance of a powerful industrial city strategy, based on the product design service concept. This model not only meets the need for applied talents for new industries under the construction of a powerful industrial city, but also meets the positioning of Bengbu University to construct an applied school.Because the most important thing about it is to enable students to carry out professional practical learning in the industrial chain, enrich the practical teaching system. At the same time, it can focus on cultivating students' practical ability and cultivate compound-type talents with innovative ability for the industry. Meanwhile, it can highlight the value of Bengbu University's creative product design services and then form a unique brand connected effect. It develops product innovation for enterprises in many ways which makes products competitive.It provides new ideas for new type industries development, promotes industry development with a service platform, which can promote economic transformation and growth, consequently promoting the construction of a strong industrial city.

\section{Funding:}

(1) Supported by Key research projects of Humanities and Social Sciences of Bengbu University ( No. 2019SK07zd)

(2) Supported by Quality Engineering Project of Bengbu University (No. 2018JYXMW17)

\section{References}

[1] Zhaoxia Jiao. Research on Countermeasures for highend development of high-tech industry in Dalian city[J].Economic outlook around Bohai Sea, 2017 (1): 12-15

[2] Xiao-fang YUAN, Yu WU.The Framework for Sustainable Product-Service System Design[J] Packaging Engineering, 2016, 37(16): 91-94.

[3] Xue-lan HE, Jian-xin XIONG. Product Design Innovation Methods Based on the Service Design[J]. Packaging Engineering, 2017, 38(20): 286-289.

[4] SECOMANDI F,SNELDERS D.Design Processes in Service Innovation[J]. Design Studies, 2018(55): 1-4.

[5] Jia TANG.Creative Product Design Elements of Hang-zhou Exploration[J]. Business, 2013(2): 195.

[6] Qian Ma. Study on the Design Value of Cultural Creative Products in Universities[J]. Science and Technology, 2017(1): 84.

[7] huishu Zhao.Connotation and contemporary value of craftsmanship spirit [J].Economic and trade practice,2018 (20): 278. 